WellBeing International

WBI Studies Repository

2003

\title{
What it is to be a Dog: A Qualitative Method for the Study of Animals Other than Humans
}

Kenneth J. Shapiro

Animals and Society Institute

Follow this and additional works at: https://www.wellbeingintlstudiesrepository.org/acwp_arte

Part of the Animal Experimentation and Research Commons, Animal Studies Commons, and the Other Psychiatry and Psychology Commons

\section{Recommended Citation}

Shapiro, K. J. (2003). What it is to be a dog: A qualitative method for the study of animals other than humans. The Humanistic Psychologist, 31(4), 67-96.

This material is brought to you for free and open access by WellBeing International. It has been accepted for inclusion by an authorized administrator of the WBI Studies Repository. For more information, please contact wbisr-info@wellbeingintl.org.

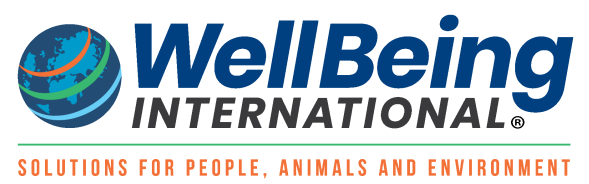




\section{What it is to be a Dog: A Qualitative Method for the Study of Animals Other than Humans}

Kenneth Joel Shapiro

"Anima-a-al!" apparently is the most vilifying invective that the playwright Arthur Miller can dredge up to signify the calumny, the otherness, the radical betrayal by his ItaloAmerican protagonist of his community (Miller, 1960). Somehow, "vegetabl-l-le!" would not do. How did animals, that is nonhuman animals (I will use the former term for the latter in this essay) gain this freighting?

Sabaka is a dog that is a member of my family. ("Sabaka" is Russian for dog.) My family is not peculiar in considering an animal as a family member, as $68 \%$ of the respondents in a study of pet-owners do so (Cain, 1985). We love Sabaka but does he love us, and how? Somewhat over one half of the households in the United States have a dog or a cat, a population of 90 million animals (Rowan, 1986). Even if some of these pet owners would not admit it if asked or even explicitly think it to themselves, I believe that most of us live with our pets as if we had a sense of their allegiance, of their feelings, of roughly, their experience. Is this sense reflective of these animals' experience (can I even use that term in speaking of animals) or is it merely reflective of our present social construction of this segment of our reality?

We have two questions: Can we know the experience of an animal -- does Marco really know what he is referring to when he attributes animality to Eddie Carbone in Miller's play; can I know if and in what sense Sabaka really loves me? Second, how did the term "animal" come to bear such an ambivalent set of images and symbols as suggested by our two examples; and, more critically to our concerns, what, if anything, is the relation of that ambivalence to the animal's actual experience?

There have been a number of attempts recently to answer the latter question, the question of the social construction of "animal," (see, for examples, Thomas, 1983 and Midgley, 1978). We will offer a brief account, highlighting one thread of this history largely as a backdrop to our primary focus on the first question. The account will build on a critique of the concept of humanism, which, as we will show, in part has defined itself to maintain a discrete categorical distinction between humans and animals. It is partly humanism that allows Miller to excoriate Eddie with the term "animal" and that leaves me in doubt about the nature of Sabaka's experience. However, by accentuating and refining a particular outgrowth of humanism, humanistic psychology, we will attempt to establish, or is it reestablish, a direct access to the experience of animals.

In a preliminary way, the body of the paper attempts to deal with the question of animal experience as a problem for method. How can we gain access to and describe with any confidence that experience? Can qualitative analysis contribute anything to ethology or animal psychology? 
Before beginning, I should give some context for this project for it is, admittedly, an unusual one in what we have come to call the human science approach to the social sciences. The paper is occasioned, symbolically if you will, by the publication of Animal liberation: a new ethic for our treatment of animals (Singer, 1975) and The question of animal awareness: Evolutionary continuity of mental experience (Griffin, 1976). Singer's work is largely responsible for launching a significant public debate over contemporary society's use and treatment of animals (and, as well, hatching a political movement -- the animal rights movement).Perhaps as much as any other, Griffin's book has challenged us to think about animals as beings with a "mental" life.

Of course, the project is also occasioned by a resurgence of interest in qualitative methods as a form of investigation of experience. My interests in this project are political and educational as well as purely investigative. I do not believe that such a broad agenda compromises the study. In fact, it is entirely consistent with phenomenological and qualitative analytic approaches that a multiplicity of horizons are necessarily present in any investigation and must be explicated as part of that study. Further, I believe that phenomenology is a critical theory in the broadest sense that it can contribute a critique of ideology that is liberationalist in intent and program.

\section{“Experience” in Animals Other than Humans}

In the ordinary course of living we sometimes relate to animals as if we know what they are experiencing. We often do so with considerable confidence as to the adequacy of our knowledge. Of course, there are also many, all too many, contexts in which we relate to them with no regard to or consideration of their experience. I will argue that the former, for the moment only apparent possibility, can be the basis of a phenomenologically based ethology.

At present few investigators or philosophers deny that animals have some form of mental life. In that sense, a radical Cartesianism is dead at least as an ontological position although see Kennedy, 1992). Of course, radical behaviorism in its heyday was methodologically if not also ontologically Cartesian in refusing to concern itself with an animal's mental life. With cognitive psychology, we have the advent of a methodological behaviorism and the position in practice that while there is a cognitive structural substrate to animal behavior, we need not concern ourselves with what if anything of that information processing machinery is lived by the animal. The metaphor of animal as machine is retained albeit substituting the modern computer for the Cartesian pulley.

The prominence of this practice notwithstanding, most of us, with Griffin, do not hesitate to impute some form of experience to most if not all animals. However, the denials that we can know animal experience with any confidence remain legion. A recent example is Nagel's argument in "What is it like to be a bat?" (1974). In my own field of phenomenological psychology, Kruger (1979) asserts that "it is impossible for man to explicate how the animal stands out toward the world" (p.28). At the same time, Kruger 
does allow that "the animal...is not contained within its skin" (p.27) and that "an animal relates to that segment of the world that is meaningful to him" (p.27).

On the other hand, Italo Calvino, a closet phenomenologist, does not hesitate to illuminate human experience with metaphors based on the experience of animals -- for example, the experience of dogs caged in the city pound (p. 11, 1982). In Approaches to philosophical biology (1965), Grene critically reviews the work of a group of Continental biologists and psychologists who took seriously the question of the explication of animal experience. As she notes, they "all share...allegiance to the phenomenological slogan: back to the things themselves!" (p. 257). In fact, several of them influenced MerleauPonty, notably Goldstein and Straus (p. 184). However, Grene concludes that aside from this indirect influence their work has been ignored.

In this paper, I focus on considerable conceptual thickets that must be cleared. Elsewhere, I have described a method and its application to the study of a dog (Shapiro, 1997, 1990). I rely on the dog as subject because with a 14,000 year history of domestication and selective breeding this species highlights the issue of sorting out our experience of a socially constructed entity as against the dog's experience as it appears to him or her. At the same time that the dog as a species bears considerable social and mythic burden as a result of its long and close association with humans, it still retains some degree of "wildness," witness how readily it becomes feral. Also, at least in some cultures it serves as a prototype for "animal." For these reasons its study aptly shows the methodological difficulties with which we must be concerned. A final reason for selecting the dog is that I am familiar with it as a species, having had one or more members of that species as a close companion most of my life.

My confidence in regard to understanding the experience of my present dog, Sabaka, varies considerably. There are many moments in which I sense without doubt that he has a particular intention, and what that intention is. Even more complexly, there are moments when I sense that he expects me to do something and, when I fail to do it, he is disappointed or puzzled, depending on the context. We have complex games and routines together. For example, midway through our morning walk, I start back across the field to the house and signal him to do likewise. He prefers to stay ahead of me and now, then, he must reverse positions with me so he can remain ahead. I clap with increasing tempo as he comes toward me, and he increases his speed. Passing me at full tilt, he always stays within a certain distance of either side of me so that I can just barely tag him, but can not stop or divert him from regaining the lead. More generally, I sense certain moves on his part in certain contexts in certain moods. My question is not how he acquired these, through what mix of instinct and learning; rather, it is what is his experience of them and, again, can I be confident enough about that to justify calling my description of it an explication of his experience.

Another example: I am quite sure last week, that Sabaka, with the two other members of our family out of town, was a bit punk, less interested in play, in going outdoors, in his food, and that he was more clingy, staying closer to me, soliciting patting more than 
usual. I do not think I was projecting my own feelings. I would be fairly secure in describing his experience in terms of some of the structures of mild depression - objects were not inviting him, he was missing something, or the like. But if I am not projecting my own sense of abandonment, am I not "projecting" at least my own version of a particular socially constructed dog -- that of the dog as a companion, a family member, as one of us and, therefore, as one bereft like one of us?

Of course, there are many moments also when I have little sense of what he is experiencing. He spends hours just lying there, staring out or vaguely watching one of us -- relaxing, waiting? I use these descriptions which are from a vocabulary of experience, but I am not sure if a vocabulary of physiology or of a nonintentionalistic behaviorism is not all that is warranted. Is there something going on from his point of view, does he have a point of view, can I know it with any confidence?

Finally, another set of problematics, there are a host of behaviors which I recognize in Sabaka, not as peculiar to him or to our relation (although there are those) but as speciesspecific behaviors. For example, he explores the field by "walking or running with nose to ground, sniffing, occasionally circling and weaving to pick up the trail", often vocalizing and wagging his tail (Fox, 1974, p. 173). Or, I recognize the complex ways he play-fights with the neighborhood German shepard -- "may turn head away (laterally or lowered ventrally) from adversary, bares teeth and 'shows eye'","...remains standing or sitting while adversary circles or incites" (p. 176). In these moments what is he experiencing, what do I know of it, and how? On his side, some of his behaviors are parts of a larger instinctive repertoire no longer available to him, as, for example certain predator behavior is now partially degenerate or only vestigial in some dog breeds (Fox, 1978, ch. 6). Further, he is using them here in play. What are the experiential concomitants, given these considerations? On the side of the investigator, what is the effect on the task of explicating experience that I recognize certain behaviors as "in the literature"? Is this literature itself merely a more subtle form of social construction of the dog; or does it give me better access to his experience? Even if I can explicate the experience of a dog, does that add anything to my understanding beyond the standard account of the ethologist?

Unfortunately, these are all genuine questions and I am open to the possibility that they are not answerable. Again, however, my beginning point is the experience, a common one, that we often relate to animals with considerable confidence as to what they are experiencing.

\section{The Social Construction of Animals other than Humans}

All animals are the etymological offspring of that peculiar class of life forms that is endowed with breath or soul (L. anima), spirit or mind (L. animus), and are quickened ( $L$. animare), that is move on their own accord. Given these enviable credentials (by comparison to "human" from L. humus for mould, ground, soil) their historical course has been less than mixed, particularly in the modern era. Ironically, despite their beginning in 
association with air and soul, it is they not us who have become dirt, dirty impulses, the sexual and excretory aspects of the body, the beast. Despite their initial association with autonomy, with the freedom of the spirit, it is they who have become object, instrument, meat on the hoof, stereotaxically fixed preparation. Geertz's (1973) descriptions may be generalized:

The Balinese revulsion against any behavior regarded as animal-like can hardly be overstressed. (pp. 420-1)

They regard animality as the direct inversion aesthetically, morally, metaphysically, of human status. (p. 419)

The social construction of the dog bears out this at best mixed history. In Asia, far from their Western counterpart, "man's best friend," the dog is a pariah (Perin, 1981, p. 70). Peripheral to the human community, his role is the dirty, scrounging scavenger (Shepard, 1978, p. 150). Worse than this symbolic casting, in more functional terms, the dog is food.

In the United States and some but not all parts of the West, the dog's symbolic burden is many-layered and fundamentally ambivalent. He (allow me the masculine here for in the West's construction canine is "he" while feline is "she") is our companion, a member of the family, a loyal friend. But he is also a "dog," an unattractive person, an inferior product, or a contemptible person (Perin, p. 74). In pre-industrial periods he was associated with the devil (Shepard, p. 109). As pet, the dog is, in Shepard's view, a "minimal animal" (p. 192), that is he is deprived of his animality, humanized, neotenized so we can cuddle him, fixated in a subordinated role to a human "alpha" that requires his continual obedience; sanitized, neutered, "shown;" exploited for his eyes (though his vision is weak), his tranquilizing effect on us, his sycophantish companionableness. Yet, for all the selective breeding and training to make him enough like us to fill our needs and whims, he remains also the beast who has only animal instincts, who sniffs, smells, and eats dirt and excrement.

Perin offers a thesis which while speculative has the virtue of offering an explanation of this simultaneous idealization and vilification of the dog. Her argument is that beneath our view of the dog as loyal companion, he functions psychologically as "transitional object" for us. As children, he allows us to leave our parents less traumatically. For some of us as adults who never completed the separation-individuation process, he provides an unconditional loving parent.

The dog is both member and property, being and object (Shepard, p. 149). His is a "duality of otherness and companionship" (p. 237). This is an extraordinary burden for one animal.

Though no doubt by comparison the cost of the burden of these complexities and ambiguities is greater to him, it is also a problem for us in the present context. For as 
would-be investigators of him we are embedded in this historically evolving cultural creation. The animal is not out there beyond our culture in a nature that is somehow simply what is there. He is a product of our social and emotional needs, fears and desires. We know him only through certain institutions (family, research laboratory, factory farm, managed game preserve, "wilderness" area), literature (fairy tales, bestiaries, nursery rhymes, natural history, sportsmen magazines, dog-training manuals), and language.

In a peculiarly Kantian and Piagetian description of human development, Shepard argues that animals are the necessary aliment for the acquisition of categorical thought. If the animal is formative of thought and language at this level, then the methodological task of the present essay would seem insuperable.

\section{Deconstructing Humanism}

This suggests that to arrive at a phenomenological description of the experience of an animal, an investigator must begin as cultural anthropologist and interpret the place of the dog in the culture in which he or she is investigator. But that account is only of interest in itself in the present context, if it is also a description of the experience of the animal. If it is not, then, having been made explicit, in a traditional methodology it can be put aside as investigator bias. However, in an interpretative anthropology more in sympathy with a human science approach, it must be conceptualized as part of a hermeneutic circle in which the text is the complete cultural representation of the animal.

On the other hand, and the more likely possibility, if the role of the dog in the culture does affect his experience through shape of institutions, forms of relationships, and selective breeding, we must take that account as a formative context of the experience of the dog. This is strange territory in which to ply an anthropologist's trade. Again, the culture to be described, that is the culture shaping the dog, is also the investigator's culture. We can readily provide an account of their institutional setting but would like more direct access to their experience of it. However, we are limited to observation and interaction with them in nonlinguistic communication, for they do not talk. Of course, that interaction is already part of the cultural account. Is there any additional and more direct access to the experience of the dog? If there is not, then, we are in effect limited to this account of the culture we and the dog share. For in that case there is no difference, methodologically, between the account of the cultural myth of the animal and the animal's experience. Our method is simply a hermeneutic phenomenology applied, again, not to the dog directly but to that text which is the cultural representation -- and so much for a phenomenology of the experience of an animal. An interpretive anthropology or a hermeneutic phenomenology is necessary but not sufficient to our purposes.

How we know an animal, at least the modern official mode and form of our understanding, is itself also arguably, though more subtly and pervasively, a dimension of the social construction of animal. Since this construction influences the modalities through which we experience an animal in this culture, we must explicate it before we can turn to the possibility of a more direct apprehension of that experience. Here we 
briefly describe a tradition, under the term "humanism," which by the logic of its development required that we know the animal from across the chasm of a categorical divide and through a method built on externality and inference - for a fuller treatment, see Shapiro (1990).

In the standard account (e.g. Kurtz, ed., 1973), humanism, a development of the Enlightenment, is a revived and revised form of the Roman "humanitas brought to bear against medieval scholasticism. In most general terms, it is a way of life centered on human interest and which takes the human as "the measure of all things." The basis of this human-centeredness is held to be reason. Reason is at once free and freeing thought. The ideal of free thought is "a method of free inquiry and critical intelligence based on reason" (Kurtz, p. 182) and a "free mind" for which the only authority and master is reason (p. 184).

A schematic history of humanism consists of a set of rival imperialisms against the claim that the center of things necessarily and rightfully belongs to human being, as follows:

\section{God}

$\begin{array}{lll}\begin{array}{l}\text { 3. Other large } \\ \text { forces: society, }\end{array} & \begin{array}{l}\text { Humanism: } \\ \text { reason } \\ \text { fistory, language thought }\end{array} & \begin{array}{l}\text { 4. Science, } \\ \text { trechnology }\end{array}\end{array}$

\section{Nature}

In the initial move, God and the supernatural are excommunicated or transformed into reason which is then invested exclusively in human being. To further consolidate this position, at the same time human is radically distinguished and separated from the "lower animals" and from nature by virtue of reason. Humanism intends to displace the irrationalism and emotionality of both the dogmatism and authority of religious tradition and the instinctual, need-dominated emotivism of the animal. Beginning notably with Galileo, nature is eventually further transformed and reduced to matter in motion, a dead although often violent body or force, and one whose significance lies in our control and use of it. Eventually and insidiously, we come actually to experience the "natural" precisely as this theoretical nature-construct, forgetting our affinity and belonging to an earlier natural rhythm and living atmosphere (Kohak, 1984, p. 8)

Of course, both of these rival imperialisms have mounted their own counterattacks: Religion in the form of fundamentalist revivals and a more genuinely nature-centered nature through environmentalism, the rise of the science of ecology, and the animal rights movement. From the environmentalist-ecological perspective humanism is "arrogant" (Ehrenfeld, 1978) for it is an inflation of the power of reason and, particularly the degree 
of control and dominance of nature that is possible under its auspices. It also treats nature as a "standing reserve" (Heidegger, 1977, p. 17), as a resource for human interests and well-being. Despite this critique even the recent, otherwise surprisingly sympathetic, treatment of nature by the sociobiologist Wilson grounds his affection in the as yet unlocked secrets of the uses of plants and animals for us (1984). Nature is a genetic medicine chest worth preserving for our not its own sake. From the animal rights perspective, humanism is prima facie "speciesist," that is its discrimination against animals is comparable in structure to racist and sexist prejudice (Ryder, 1975, p. 5). Putting it even more strongly, Jamieson argues that for the humanist "animals do not matter" (1985, p. 9).

The third quadrant of our diagram is a set of challenges to humanism which postdate it. While straining our location of them together, in common each is a larger force that threatens to encompass and decenter the human subject. With Hegel, history, with Marx and with modern sociology, certain institutional forms, constitute larger forces which shape us and within which we are embedded. More recently, language itself has become a force which threatens to displace humanism's foundation in the autonomy of reason and of the intentional subject. Structuralism, post-structuralism, and Foucault's archaeology share an anti-humanist position (Sheridan, 1980, p. 90). Whether construing language as structure or event or act, they all give it a status to which the human subject, for example, as authentic author, and human consciousness are subordinated. "Man" is the conduit of language, or "man is an invention of recent date" (Foucault, quoted in Sheridan, p. 88).

While very dissimilar in other ways, rebutters from these three quadrants (call them, respectively, religionists, nature advocates, and postmodernists) share the critique that humanism's claim in regard to human being is a categorical overcorrection. It is a distinction overdrawn and one-sidedly inflated at least one of several interfaces -human/God, human/animal, or human/society.

The fourth quadrant is peculiar in that in origin it is most directly itself a product of humanism. Through much of the modern period science and technology were conceived as extensions and handmaidens of human reason, serving to vouchsafe the distinctiveness and the preemptive value and centrality of human interests. In more recent times a critique of science, particularly of scientific humanism, of scientism, and of the overapplication of the technological fix, has emerged. In that it takes aim at positively or absolutely founding knowledge in reason, this critique of science is also a critique of the claims of humanism. Eventually, complex tensions developed between science and technology, and humanism. Ironically, humanists themselves have been prominent among critics of science and have beat a strategic retreat to a new ground where human being is redefined less exclusively in terms of reason and science. In this neohumanism, while not quite taken as Frankenstein's monster, science is recognized as a limited and an only human enterprise, and one which, if not bridled, can have a depersonalizing and, precisely, dehumanizing effect. In turn, science and technology find this neohumanism fuzzy and indeterminate. 


\section{Critique of Humanistic Psychology}

In this context, we turn to a critique of humanistic psychology and, eventually, to a recasting of its rendering of the human that can support the possibility of direct apprehension of the experience of an animal. Humanistic psychology, the "third wave," is a reaction to behaviorism and psychoanalysis. In behaviorism, it finds a science of human behavior that is too mechanistic and reductionistic in its method and its form of explanation. In both of the two waves, it finds a devaluation of the human by association with animals (rat psychology) or the animal in human, the instinctive, the merely biological (the classical Freudian unconscious). Rather than trust in extrapolation from animal psychology or ground a humanistic psychology in the "beast in man," this psychology is based on, presumedly, peculiarly human capacities and potentialities such as creativity and values.

With respect to classical humanism, this new humanism broadens the concept of reason to the inclusion of all consciousness or experience, and to an emphasis on "visceral experiencing" (Rogers, 1980, p. 159), or "felt-meaning" (Gendlin, 1962), or to "what you really feel..." (Barton, 1974). The earlier valorization of freedom is retained but is shifted from free reason to the free self. Self definition and self development are the essentially human task. An individual accomplishes this superordinate goal through a natural unfolding and expression of the given potential self. This process of self actualization requires freedom of the self from external, that is social, determination. This highly individualistic vision of human being may be interpreted as an Americanization of classical humanism. Clearly, Rogers' work continues the line of Emerson's self-reliance, Thoreau's retreat from and disavowal of society's laws and ways, and Whitman's "I celebrate myself...", with its own brand of optimistic faith in individual potential. A recent essay (Marx, 1987) describes this Emersonian revival, although without connecting Rogers to it.

Developments from within humanistic psychology have since attempted to complement this image of the self as encapsulated with the belated recognition that individual growth is necessarily a function of reciprocal influence between individual and society (Simpson, 1977).However, critics of this American psychology still take it to task for its promotion of narcissism (Lasch, 1979) and for its "sanction for selfishness" (Wallach \& Wallach, 1983, Chs. 7, 8).There is some agreement that humanistic psychology has not actualized itself and is in crisis (Giorgi, 1986).

The present critique argues that one reason for this is its continued tight clasp on a concept of self actualization that renders the self not merely hyperindependent and egocentric but, more importantly, too internal, too dissociated from the world. Instead of a faith in an essentially encapsulated self that is ideally only nourished, not formed or even coconstituted by the world, there is available in humanistic psychology itself the kernel of a more adequate concept of self founded in empathy. 
Unfortunately, both the role and concept of empathy available in humanistic psychology have problems. Even for the later Rogers, despite its titular role as "a way of being" (1980), empathy remains a therapeutic and educational tactic, a means to the end of reaching self actualization. While it is claimed that the actualized self tends toward altruism, community, and empathy, the latter is not taken as the primary constitutive feature of the experiencing self. The therapist/teacher is empathic so that the client/student is enabled to be more sensitive to an experiencing self known through an internal focus. The client does not become the therapist or as the therapist; he becomes a unique self that was somehow already and internally there waiting to be realized.

Even given this secondary, merely therapeutic status, empathy is not adequately described and, importantly for our concerns, its methodological implications are not realized. Rogers would have us know our client through empathy; but for the client, that is the everyday individual, the world is not known through empathy and the self is not the correlative of that world so known. Nor is systematic investigation of that world, or of "clients," or of therapies conducted through empathically based methodologies. Rogers, the humanist, would not quite let go of an investigatory method (as distinguished from a therapy) based on the classical concept of reason. He would not allow a view of the individual or the investigator as radically embedded in the world perhaps because, for him, that was a too perilous risk to the freedom of the self. Even Rogers' optimism has a limit.

What we are suggesting is that in addition to a categorical overcorrection, humanistic psychology, for all its significant revision of classical humanism and even its critique of a certain scientism that developed from it, retains, along with philosophical humanism, a methodological overcorrection, the faith in reason. The concept of rationality resulting from the original impulse of humanism against supernaturalism and church dogmatism developed into the natural scientific ideal of objectivity, conceived as neutral externality. This approach featured an investigatory posture that is independent and unbiased. However, the cost of achieving that objectivity was to limit the investigator to knowledge by inference, to a set of externally observed data upon which the power of inferential logic or reason could be and had to be applied. With this posture, the investigator denied himself or herself the use of empathy, that is, most broadly, an understanding based on direct apprehension or intuition of the object. In this context Rogers' humanistic psychology is a partial restoration of empathy largely confined to the therapist in the safety of his or her consulting room.

Of course, in the literature of existential phenomenology there are available at least two seminal accounts of empathy which give it a more genuinely constitutive status for human being and a potentially more radical role in an investigatory enterprise: Heidegger's description of dasein as an open responsiveness and attunement that lets be (1962) and Merleau-Ponty's notion of inhabitation (1962). In fact, Levin's recent attempt (1985) to "flesh out" Heidegger's interpretation of dasein by, in effect, explicating its concrete bodily pole offers a refinement of humanistic psychology that is similar to that 
offered here. In this humanism, "The ecstasy of [dasein's] primordial openness is at last proclaimed, and the self-enclosed Cartesian Self is exploded..."(p. 26).

For the Merleau-Ponty of Phenomenology of perception, the body is the condition for the possibility of an openness to the world, although not Heidegger's primordial openness. Through its mobility, we can virtually inhabit an object in the world; we can know it from its own point of view, as if it could see. This rendering of empathy as inhabitation is not limited to the apprehension of the physical-based vantage points of inanimate "viewers" (in his example, the lamp on the table's view of the chimney [p. 68]). Sociality is based on our inclination to inhabit each other's point of view in the full sense of that term -- the style and substance of each other's intended world. Bodily inhabitation occurs in a region of experience that is prelinguistic yet meaningful, being precisely our sense of the meanings or the structures of a situation which are not yet in words. Elsewhere, I have attempted to describe how this possibility of bodily inhabitation can be the basis of a phenomenological method (Shapiro, 1985). Here we should clarify only that this possibility of meaning that is not in the moment mediated by language does not imply that the lived body is prior to or uninfluenced by language. Part of the way the lived body becomes informed, that is achieves an embodied sense of situations, is through a dialectic relation with language. However, in the moment, again, the mobility of the lived body is the vehicle of the direct apprehension of another's point of view. Through it we can directly take up another's intended world.

To sum this section, we have argued that humanism is a pervasive way of life that subtly but radically provides a social construction of "animal" wherein that class is categorically segregated from the class human by virtue of the latter's exclusive hold on reason. Ironically, this chasm is further supported and maintained by the view, also a development of humanism, that we can only know animals through an application of the very reason that separates us. We can only know an animal confidently by inference -through a rational mediating act applied to objective observation. Direct apprehension or intuition of the animal is suspect in principle and, eventually, becomes less available in practice. Any empathic move with respect to an animal is construed as an atavistic animism or, at best, a personal projection, particularly of those nonhuman, that is unreasonable, that is animal aspects of the human self.

There is a parallel in this argument with that of Foucault's account of the social construction of "madness" or "mental illness" (1965). More particularly, I have noticed certain parallels in the history of our treatment of the mentally ill and of laboratory animals -- the historical sequence: warehousing, custodial care, humane care, genuine institutional reform, deinstitutionalization.

Finally, we have suggested that the beginnings of a recovery from philosophical humanism's twin errors of categorical and methodological overcorrection can be found in humanistic psychology through a shift in focus from self-actualization to a notion of empathy recast, in phenomenological terms, as inhabitation. 


\section{Direct Apprehension of an Animal's World}

With this, we are left with the two questions, among others: Does an animal have a point of view in anything like a full sense of that term, and can we in any meaningful and verifiable sense inhabit it?

The thrust of the present paper is to develop the case that an answer to the first question requires a methodology built on an affirmative answer to the second. However, the clear drift of contemporary literature in animal research is toward the "discovery" of greater and greater intellective, communicative, and social organizational capacities of animals. For example, in the Chimpanzees of Gombe (1986) Goodall reviews the literature on such capacities in chimpanzees under such headings as "symbolic representation," "concept of self," "inferring purpose in others," and "intentional communication." These findings strongly suggest that such sophisticated ways of living are not lost on the animal, that the individual animal lives a world from a point of view the structures of which reflect that sophistication.

While as a humanist (Madison, 1981; Rabil, 1967) Merleau-Ponty is within the tradition we have criticized, he allows animals an awareness approximating a point of view on the world. The humanist Merleau-Ponty did maintain a discrete distinction between animal and human, between, respectively, the vital and the human orders (1967, pp. 129-184). The vital order includes both syncretic and amovable structures of behavior, while excluding the symbolic structures preserved for the human order. However, even the behavior of an "organism" of the vital order demonstrates a sensitivity to "situations," to a milieu that is "only virtual," to a situation that has relational and configurational significance. The organism maintains an equilibrium, in the presence of a given milieu, that is determined by "a general attitude to the world" (p. 148). The movements of the animal can embody "different attitudes of the organism to the world..." (p. 149. quoted from Goldstein). We take this to mean that the animal lives in the world as a center of action, a subject, and a point of view.

With the support of both contemporary research and Merleau-Ponty, we turn, then, to the second question: how can we get at these vital significances, these attitudes, these points of view? Traditional approaches to animal research reveal several distinguishable investigatory and explanatory styles. In the behavioristic approach, the investigator proceeds as if animals are unintentional, without point of view; or, at least, as if an account of such would not advance our understanding of their behavior. Explanations are couched in terms of environmental stimuli that sustain behavior. A more functionalist or evolutionist explanation builds a broader account in which patterns of behavior are intelligible in terms of their survival value.

Particularly with the decline of behaviorism and the rise of cognitivism, a third approach, that of physiological psychology or psychobiology, allows mental state to be associated with behavior. However, both behavior and mental state are reducible to brain state. Typically, this investigator manipulates the environment, often a chemical stimulus, to 
induce behavior from which mental state is inferred. Then, he or she explains that behavior/mental state at the level of physiological mechanism. Explanation combines the two inferences -- changes in neural state implies behavioral change which implies change in mental state. For example, a depressive state is implied by behavior which is itself derivative of depletion of a certain neurotransmitter. At least in principle, here we are twice removed from any reliance on the direct apprehension of the experience of depression. In practice, this approach begs the question of the original identification of that behavior to be operationalized as depressive.

Clearly, in these three styles the experience of the animal is, at best, of secondary interest, for, being conceived as epiphenomenal, its status is only derivative. At least in its early development, a fourth style, that of ethology, "retained an appreciation of the perceptual and inner worlds of animals" (Burghardt, 1985, p. 914). According to von Uexkull, one of its originators, "...the first task of Umwelt research is to identify each animal's perceptual cues... and to build up the animal's specific world with them" (1934/1957, in Schilder, ed., p. 13). The identification occurs through a manipulation of the environment from which can be deduced those features that are meaningful to the given species and are, therefore, by definition constitutive of their particular Umwelt. Here, the eventual account of the animal combines functionalist and experiential styles of understanding. "Biological significance" and sensibility or meaning are indistinguishable: "...Relations of meaning are the only true signposts in an exploration of Umwelten" (p.40). However, while the account consists largely of a description of lived space and time, the method consists of a "building up" of that life-world from the location of features of the environment to which the animal is sensitive. This is largely a deductive process in which the investigator infers perceptual capacity, for example, from observed performance. There is no mention of a direct apprehension of an animal's intended world. Even the use of analogy from human experience is explicitly avoided.

However, an early comparative psychologist, Lloyd Morgan, did describe "a doubly inductive process" (Burghardt, 1985, p. 912) in which inference from observation is further interpreted by "subjective induction." The inference from behavior to subjective state is complemented by a second induction based on an analogy between the investigator's own experience, were he in the animal's place, and that of the animal's presumed subjective state. Like those of the early ethologists', Morgan's suggestions in this regard have been virtually forgotten. An even earlier approach and one even more sympathetic to phenomenology is that of Goethe (Bortoft, 1986).

From our present standpoint, again, we are struck by the minimized, really absent, explicit or formal reliance on our direct sense of the experience of an animal. Clearly, it is inference that has eclipsed any possible role for direct apprehension in investigatory posture. We assert that this favored approach, historically, is in part the result of humanism's separatism, founded in the claim that with regard to rationality only humans need apply. A second resultant bias in these approaches is less blatantly speciesist but as insidiously separatist and distantiating in effect. Having defined human largely in contradistinction to animal, investigators both select topic areas and construct research 
variables in terms of these categorical distinctions. For example, we frame the study of language in animals with a certain definitive notion of the syntax of human language. Ironically, so biased, we generally find ourselves in retreat for as our estimate of the capacities of animal powers enlarges, we must constrict our placement of the categorical battle lines between human and animal: if not rationality, language; if not language, syntax; if not syntax, symbol manipulation; if not that, self-awareness... As Clark (1984) states, "it is not that we have discovered them to lack a language but rather that we define, and redefine, what Language is by discovering what beasts do not have" (p. 96, his emphasis).

While not in direct response to the speciesism and cryptospeciesism of these investigatory biases, in recent times there have been several calls that effectively might mitigate the powerful vestiges of humanism's methodological and categorical overcorrections. Burghardt (1985) calls for a broad based investigatory posture, which includes "imagining being the animal." However, he only allows that this eclectic posture be generative in function, while the real stuff of doing science, developing testable inferences, must follow on that. In her seminal and comprehensive account of her work with chimpanzees, Goodall (1986) directly allows a role for empathy but, again, it is limited to a generative function: "Subtle communication cues denoting slight changes in `mood' or attitude.... are more readily detectable once empathy...has been established...."(p. 58). "Intuitive interpretations,...stemming directly from empathy with the subject, can be tested afterward against the facts set out in the data" (p. 58). This is close to the mixed methodology I will suggest below, but stops short of giving any verificatory standing to empathy or to the investigator's sense of the animal's experience taken against the evolving interpretative account.

Griffin (1981) calls for a "cognitive ethology" which would capitalize on the animal's consciously intended communicative behavior as a "window on the minds of animals" (pp. 149-157). For Griffin, such direct two way communication in a sense would bypass the problem of knowing animals through direct apprehension and no doubt is a suggested methodology motivated to do just that. His skepticism here gives at least a partial nod to Nagel's blanket rejection "...of the possibility of knowing an animal's point of view" (Griffin, p. 160).

Nagel issues his own call under the slogan "objective phenomenology" (1974, p. 449). While less than clarion in its positive program, the call for an objective phenomenology clearly denies "dependence on empathy or the imagination;" rather, this phenomenology must rely on "concepts alternative to those we learn in the first person..." (p. 449). For Nagel, there is something that it is like to be an animal, for example, a bat; but, while bats have experience, we humans can not know it for we are not "sufficiently similar" to them. The bat's experience is grounded in a "species-specific viewpoint" (p. 445) which we can only know from our own radically different species specific point of view. For example, "bat sonar, though clearly a form of perception, is not similar in its operation to any sense we possess, and there is no reason to suppose that it is subjectively like anything we can experience or imagine" (p. 438). 
Incidentally, this is a poor example for we can orient ourselves better spatially in a room when, blindfolded, we make sounds (Ihde, 1986); that is we have a crude echolocating ability and, presumably, then can imagine, if crudely, the bat's sonar based sense of space. A better example would have been the alleged sensitivity of some migratory birds to magnetic fields. However, granting we can only know the bat's and any other beings, including my brother's, point of view from our own point of view, the question remains whether there is any gain in understanding from our attempts to inhabit that point of view or, through imaginative variation, to examine systematically approximations to, say, a different form of perception.

It seems arbitrary to emphasize the differentness when one crosses the human/animal species line while implying the reign of similarity and hence experiential accessibility within our own species across, say, historical epochs, language or cultural barriers, or even age differences within our species. Is there the same categorical overcorrection lurking here? Both we and the bat are embodied consciousnesses; we both move, know the world through our movement, have a possible sense of our moves, and the like. Can't I have a direct meaningful sense of the bat's moves and correlative world?

While offering some opening for the application of qualitative methods to the study of animals, at best the various calls reviewed are reminiscent of the tentative place of phenomenology and other qualitative approaches in the early 60s in the study of humans. Recall MacLeod's hesitant claim for a phenomenological psychology that it might serve a "propaedeutic," in the sense of merely preliminary, function for a science of psychology (1964, in Wann). More boldly, the present call, claims a robust rather than merely generative or preliminary role for qualitative methods in the study of animals. Perhaps we required the gains in both philosophical and methodological sophistication of the twenty years since the Wann volume to make bold this claim.

In a different context, Sheridan states, "I no more apprehend my dog's guilt or joy from inferences from behavior than I apprehend the inner state of humans by making inferences from their behavior" (1973, p. 20). We suggest here a regulative ideal grounded in the possibility of the direct apprehension of the experience of an animal. We adopt this approach precisely as a regulative ideal, that is clear that while we can not reach it, we are now methodologically in a position profitably to move toward it. We need no longer deny our access and relatedness to animals.

\section{Common Shared Culture}

Perhaps part of the readiness for this full opening onto animals is an offshoot of or in the same spirit as emerging feminist thought with its emphasis on belonging, relating, and caring as bases for understanding and ethics.

We can indicate the bases of this claim through a concept of sharing. Describing what we share with animals can further ground the common experience of directly knowing an animal with which we began and begin to offset the various possible errors to which that 
direct sense of them is subject, such as personal projection, anthropomorphism, and social construction. We intend "share" in an experiential sense wherein two beings both know the same thing or both know something in similar ways -- as, respectively, we both can experience that tree, or we both can see things like trees. A weaker sense of share, a loosely metaphoric usage, refers to common occupancy without implying common experience, as two trees share the same woodlot. By indicating what we share, we are making the case, against Nagel, that humans and animals are `sufficiently similar' for us to gain in our understanding of them by taking up their point of view.

We divide this region of sharedness into the classical Gallic three parts largely for expository reasons. First, although in a limited and complicated sense, we do share a culture with animals. As we have described, part of our social construction of reality is the construction of "animal." In turn, that construction is increasingly a shaper of the experience of animals and we, then, share that culture with them.

We institutionalize that complex and ambivalent construction in the forms of our socialization of animals, of our "production" and "management" of them and of their habitat and housing, and in our selective breeding and killing of certain species and individuals. While arguably built on what was already or at least potentially there for them, this may be only trivially true in the instance of recent attempts to genetically engineer them. This construction constitutes part of their experience and to understand them we must know it.

We have already discussed some of the problems and limitations in an interpretive anthropology or a hermeneutic approach to that text. We indicated that a hermeneutic approach is a necessary but not a sufficient step in understanding the experience of an animal. Further, we have the problem analogous to that of the adjusted slave. Are we to understand the slave as a submissive being, as he submits to us; or does his bondage largely conceal him from us? On the one hand, our construction of the animal influences and is part of the animal's experience. But our construction of, for example, the laboratory animal as object, instrument, measure and preparation is not simply and directly transposable to the animal's experience for this particular construction precisely denies that, any, and all experience to the animal. It is partly that denial that allows the scientist to do his or her experiment. Yet surely the lab animal is an experiencing being despite this construction. While his experience is shaped by that construction, we can not simply say he lives himself as calibration or instrument or as animal model of some aspect of us. On the other hand, we can not locate or understand the animal outside of that or any particular cultural setting in which he lives. Surely, there is no pure telos of dog independent of setting. Yet, no particular setting shapes the animal except in conjunction with certain instinctive patterns brought to and interactively played out in the setting.

These problematics and qualifications notwithstanding, my companion Sabaka and I clearly share a common society the shape of which is a complex product of both him and me. Part of the ground of my direct apprehension of his experience is that common shared culture. 
Given these complex relations between the social construction of the animal and his experience, however, it is prudent for us as investigator to begin with a method that reads and interprets the text of that construction. That text is the institutional arrangements and the language with regard to animals in this culture. Informed by this initial hermeneutic approach, using it as a fore-understanding, we can better establish certain aspects of that construction which we can expect the animal to share with us. For example, if he is constructed as trainable, he may have an experience of being trained and of being in a trainer/trainee relation. As we have described, we can also identify those aspects of the construction that precisely prevent us from being open to his experience and/or bias us with human-centered categories with respect to that experience. Again, understanding that text is only preparatory to understanding the experience of a particular animal. It can not give us and it is not synonymous with that experience.

Of course, all categories are our, that is, human categories in the sense that they mean as we intend them. However, this is not to say that we are the measure of all things for all categories presuppose the world originally occasioning them - a world that is continually both informed by but no less informing them. Again, the regulative ideal here is that of traditional phenomenology. Even if we require an initial hermeneutic detour, we can bracket present categories and return to the things themselves as touchstones to revivify and if necessary recast those categories. The touchstone here is our sense of an animal's experience. While informed by the social construction of reality that includes "animal," we do not then reduce a particular animal to a symbol-carrier, to a fable that embodies or illuminates human feelings, morality, or ways.

\section{Common Shared Nature}

Also in a limited and complicated sense we share a natural world with animals. Following Grene (1965) and Kohak (1984), we must distinguish between a primary and secondary dwelling in nature -- roughly between nature as our immediate ecological and biological setting and a socially constructed nature, nature as currently defined in our culture. Clearly, since Galileo, we have come both to think and to dwell in a natural world as "geometric shapes" (Grene, p. 14), as "matter in motion" (p. 18), and as "a system of dead matter propelled by blind force" (Kohak, p. 6).

More subtly and concretely, as I walk the Maine woods behind my house, I am living the trees as fuel for my woodstove. I imagine a particular tree downed, with a certain dryness and a certain width for my chainsaw. I actually apperceive it as to-be-cut certain lengths to fit the stove. Catching myself, I recall a different sense that I had forgotten, sometimes long forgotten. I then see a tree growing, as it were, for itself, growing toward the sun and reaching down deeply into the moisture of the earth. "Our estrangement from nature is no longer conceptual only: it has acquired an experiential grounding" (Kohak, p. 23). Seeing woods framed by my woodstove and chainsaw is a certain way of being in nature. To return to some more natural order requires more than bracketing a theory for the theory as lived provides a secondary dwelling. 
But we can be sensitive to a different night than the night created by urban lights -- a night as palpable in its own way as that night on the town; or to the stillness in the woods when the sun is high, to the rhythms of day and night, and winter and summer. We can sense these certain timings as distinguished both from any particular social construction of time and from my own existential or personal time. We have indicated that in some ways and areas we share with animals a constructed culture, as, for example, my business time, the temporal structure of my work day, is part of the rhythm of my dog's life. But we also live in and share the same natural order -- the short days of the long Maine winter, the claustrophobic irritation of black fly season, the exhilaration of a long trek in the woods and the relaxed flop down together fatigue that follows it. Sensitivity to these rhythms and to these vital capacities, rather than to the rhythm of the chainsaw's cutting or even the fuel's burning, is a more directly participatory and a less constructed way of being in nature.

While both we and animals have a socially constructed body, we also both have a natural body. I can comprehend the dog's natural body, for example, his instinctive behavior patterns, through traditional "natural" scientific approaches. But I also can have a more direct and immediate sense of that so-called hardwiring as and to the degree that it is presently lived by my dog. I claim we can do that as investigators because we are "sufficiently similar" to animals in that we both have bodies that belong to and are sensitive to the same natural order. Between the dog as a status symbol before my neighbor and my dog as the evolved degenerated remains of his presumed wolf ancestors, there is a presence of Sabaka, a particular dog, as certain rhythms, sensibilities and patterns of action. We are adding here, then, the suggestion that we can be sensitive as investigators to a present natural being as he or she lives the natural order simply because it is the common natural order.

The third region that we share with animals runs across the first two and is a precondition for them. Animals live largely in a prelinguistic and prereflective domain between language and instinct, and between, as it were, rationalism and behaviorism. I can not enter these arguments here but I am not denying some form of language to animals or even some form of reflection (Gallop, 1977). I am resting on the assertion of the qualifier, "largely."

Stated positively, animals' intelligence and thought, their sense of things, their relation with things and others, is largely in the region of bodily experience. For example, it consists of familiar paths to be traversed, of territory staked out, of felt relations -- all known implicitly and bodily. In general, an animal apperceives objects and other beings in the landscape as a motor physiognomy for which he or she has correlative motor intentions and projects. "A cat playing with a ball..., confronts the ball in a fashion different..., from the way in which the ball confronts the cat" (Grene, p. 74).

Consider Sabaka and I at play in our "den" (a mixed natural/cultural play/living room that we share). We are both on all fours; the object of the play is usually for me to catch him or to get something from him. It is old hat for both of us. We know each other's moves, 
including feints and deceits such as individual susceptibilities to distraction; we know the paths traversed, the paths prohibited physically or by custom to one or both of us -- the table I can not fit under, the sofa he is not allowed on. We know each other's body, our respective bodily capacities and limitations, inclinations, temptations, irritations, intimidations, and the like.

In the midst of the game, I do not know or anticipate his moves by inference -- although if I stepped back I could infer some of them. Rather, I know the potential space of his moves by inhabiting his bodily potentialities and inclinations. I know his moves by empathizing with him in a broad sense of that term that takes "feeling with" to refer to his vital significances, attitudes and point of view. I (and he) recognize what he, and what I in response, might do before giving a reason for it. Empathy is not limited to affective life nor to some perceptible surface of the other beneath which lurks an inner life only suggested. Rather we can empathize, kinesthetically, body to body, with a desired position or an intended behavior.

The animal's experience is of a phenomenal field, of a possible lived space with respect to which he is a center of action. On a bodily, implicit level, he opposes himself to things (has them, precisely, as ob-jects); he takes up a position and establishes a place -- his home or den or playing room or territory. Our primary access to the experience of an animal is through our empathic apperception of his or her lived body and its correlative lived world. We share with them a bodily intelligence, a bodily sense of the world. Through our lived body, in the fullest phenomenological sense of that term, we can know their body. I can know Sabaka's sense of and quiet frustration at barriers, his sense of release when the barrier is removed; of familiar paths traversed, of the cautious excitement of exploring a new field; of places to wait, to sleep, or to hide; and of how quickly he forgets a moment of pain while for how long he remembers and seeks to avoid the next possible occasion of it.

With all this talk of what we share with animals and with this claim to an intimate access to them through their and our lived body, I yet need not take the position that humans are indistinguishable from animals. In the other direction, asserting such distinctions does not require that I deny that we also are animals. Of course, in making any such distinction between human and animal being, I open myself to the charge of the speciesist forms of humanism of which I have been so critical.

Following Shepard (1978), I take the position that human being is, to use his structuralist term, a "boundary form." "We live in a lifelong tension between our humanity and our animality" (p. 90). Traditional humanism denies this tension and this ambiguity by devising an overdrawn and unequivocally separatist distinction between human and animal. The present position, then, is a corrective to the categorical overcorrection at the base of traditional humanistic thought and clarifies the impetus and eventual failure of that and other attempts at such dichotomies. We are human and animal, and have clothed ourselves literally and ideologically to hide that fact. But our "flesh" (Merleau-Ponty, 1968) is the flesh of the same world. The distinguishing ambiguity of human experience 
is not that we are subject and object, at once toucher and touched (Merleau-Ponty, 1968) for other animals are also both object or thing-like and "subjects of a life" (Regan, 1983) who inhabit the world and other beings. However, unlike us, they can not reflect on their empathic belonging. The animal "... is a self, but does not yet have a self to which in turn it can take a stand in reflective awareness" (Grene, p. 99, her emphasis).

This difference allows us to posit our closeness to them and to recognize the fact of our direct access to them. While the most insidious forms of exploitation can follow upon this reflective empathy, it is also the ground of the possibility for respect. Thus, it is the basis of an ethic that affirms other ways of being. This difference also allows us to recognize that animals, lacking a robust reflective awareness of self, are more vulnerable ontologically than we are. Their particular being is more radically contingent on setting than is ours for, unlike us, they can not reflect on any setting and from that develop a definitive self-account. A lion in a cage is not a lion. Without some semblance of lion country, as it were, without the opportunity to realize certain instinctive and acquirable needs and behaviors, the lion is a different animal. This ontological vulnerablility of animals is part of our ethical burden with respect to them. According to this analysis, beyond the traditional goal of diminishing suffering, current efforts to liberate animals must be concerned with the preservation of the being of an animal in the most radical sense.

\section{A Phenomenological Ethology}

In conclusion, I am calling for a phenomenologically based ethology, the touchstone of which would be our sense of the experience of an individual animal. The method begins with a dual hermeneutic detour: an interpretative reading both of the text of our social construction of the species and of the category of animal in which the culture has placed our subject (a pet dog, a laboratory rat, a factory-farm chicken), and of the text of traditional natural scientific findings potentially applicable to an understanding of that individual animal. As we have indicated, these readings serve a generative or facilitative function as they open us to those aspects of the social construction of the animal which may influence his or her experience. They also serve a critical function of identifying postures toward the animal that may prevent us from being open to the experience of the particular animal subject and, more generally, to the immediate ecological and biological setting we share with the animal. The hermeneutic reading prepares the way for the assumption of a bodily empathic posture. However, that posture constitutes the primary orienting and verificatory approach in this phenomenological ethology. We are arguing that only through it is a direct apprehension achieved. This empathy is possible because of the actual and virtual mobility of the lived body and because, by way of a lived body in common, we share with animals a prelinguistic region in which meaning, both natural and cultural, is lived and bodily sensed.

The general research program can involve empathic participation through "observation" or participant observation of an individual animal, or a group of animals of the same species, or mixed animals in a particular circumstance or setting, or animals involved in a 
unique set of events. The product of the inquiry is a structural descriptive or narrative account of the experience of an animal or group of animals. That account can claim to be of that animal's experience only, or typical of a group of animals, or of animals in a certain circumstance, or even of all animals. Verification criteria can include traditional testing of predictions but, in the final analysis, must appeal to our sense of the experience of the animal or animals.

\section{References}

Barton, A. (1974). Three worlds of therapy: Freud, Jung and Rogers. Palo Alto, California: National Press Books.

Bortoft, H. (1986). Goethe's scientific consciousness. Tunbridge Wells, England: Institute for Cultural Research.

Burghardt, G. (1985). Animal awareness: Current perceptions and historical perspective. American Psychologist, 40, 905-919.

Cain, A. (1985). Pets as family members. In M. Sussman (Ed.), Pets and the family (pp. 5-11). New York: Hathorn Press.

Calvino, I. (1982). If on a winter's night a traveller. London: Picador.

Clark, S. (1984). The moral status of animals. Oxford: Oxford University Press.

Ehrenfeld, D. (1978). The arrogance of humanism. New York: Oxford University Press.

Foucault, M. (1965). Madness and civilization. London: Tavistock.

Fox, M. W. (1974). Understanding your dog. New York: Bantam.

Fox, M. W. (1978). The dog: Its domestication and behavior. New York: Garland.

Gallup, G. (1977). Self-recognition in primates. American Psychologist, 32, 329-338.

Geertz, C. (1973). Interpretation of cultures. New York: Harper.

Gendlin, E. (1962). Experiencing and the creation of meaning. Toronto: Free Press of Glencoe.

Giorgi, A. (1986). The crisis of humanistic psychology. Washington, D.C.: American Psychological Association Convention. 
Goodall, J. (1986). The chimpanzees of Gombe: Patterns of behavior. Cambridge: Harvard University Press.

Grene, M. (1965). Approaches to a philosophic biology. New York: Basic.

Griffin, D. (1981). The question of animal awareness: Evolutionary continuity of mental experience. Los Altos, California: William Kaufmann.

Heidegger, M. (1962). Being and time. New York: Harper and Row.

Heidegger, M. (1977). The question concerning technology and other essays. New York: Harper and Row.

Ihde, D. (1986). Texts and the new Hermeneutics. Warwick, England: Conference, Narrative and philosophy: The recent work of Paul Ricoeur.

Kennedy, J. (1992) The new anthropomophism. Cambridge: Cambridge University.

Kohak, E. (1984). The embers and the stars: A philosophical inquiry into the moral sense of nature. Chicago: University of Chicago Press.

Kruger, D. (1979). An introduction to phenomenological psychology. Pittsburgh: Duquesne University Press.

Kurtz, P. (Ed.). (1973). The humanist alternative: Some definitions of humanism. Buffalo, New York: Prometheus.

Lasch, C. (1979). The culture of narcissism. New York: Warner Books.

Levin, D. (1985). The body's recollection of being. London: Routledge \& Kegan Paul.

MacLeod, R. (1964). Phenomenology: A challenge to experimental psychology. In T. Wann (Ed.), Behaviorism and phenomenology (pp. 47-74). Chicago: University of Chicago Press.

Madison, G. (1981). The phenomenology of Merleau-Ponty. Athens, Ohio: Ohio University Press.

Marx, L. (1987). A visit to Mr. America. New York Review of Books, 34, 4, pp. 36-39.

Merleau-Ponty, M. (1962). Phenomenology of perception. New York: Humanities Press.

Merleau-Ponty, M. (1963). The structure of behavior. Boston: Beacon Press. 
Merleau-Ponty, M. (1968). The visible and the invisible. Evanston, Illinois: Northwestern University Press.

Midgley, M. (1978). Beast and man: The roots of human nature. Ithaca, New York: Cornell University Press.

Miller, A. (1960). A view from the bridge. London: Cresset.

Nagel, T. (1974). What is it to be a bat? Philosophical Review, 83, 435-50.

Perin, C. (1981). Dogs as symbols in human development. In B. Fogle (Ed.), Interrelations between people and pets (pp. 68-88). Springfield, Illinois: Charles C. Thomas.

Rabil, A. (1967). Merleau-Ponty: Existentialist of the social world. New York: Columbia University Press.

Regan, T. (1983). The case for animal rights. Berkeley: California University Press.

Rogers, C. (1980). A way of being. Boston: Houghton-Mifflin.

Rowan, A. (1986). From the director. Tufts center for animals newletter, 1, 3, p. 1.

Ryder, R. (1975). Victims of science. London: Davis-Poytner.

Shapiro, K. (1997). A phenomenological approach to the study of nonhuman animals. In R. Mitchell, N. Thompson, \& L. Miles, (Eds.), Anthropomorphism, anecdotes and animals (pp. 277-296). Albany, NY: SUNY.

Shapiro, K. (1990). Understanding dogs through kinesthetic empathy, social construction, and history, Anthrozoos, 3, 3, 184-195.

Shapiro, K. (1990). Animal rights versus humanism: The charge of speciesism, Journal of Humanistic Psychology, 30, 2, 9-37.

Shapiro, K. (1989). The death of the animal: Ontological vulnerability and harm, Between the Species, 5, 4, 183-195.

Shapiro, K. (1985). Bodily reflective modes: A phenomenological method for psychology. Durham, North Carolina: Duke University Press.

Shepard, P. (1978). Thinking animals: Animals and the development of human intelligence. New York: Viking Press.

Sheridan, J. (1973). Once more from the middle. Athens, Ohio: Ohio University Press. 
Simpson, E. (1977). Humanistic psychology: an attempt to define human nature. In D. Neville (Ed.), Humanistic psychology (pp. 67-87). New York: Gardner Press.

Singer, P. (1975). Animal liberation. New York: New York Review Press.

Thomas, K. (1983). Man and the natural world. New York: Pantheon.

Von Uexkull, J. (1934/1957). A stroll through the world of animals and men. In C. Schiller (Ed.), Instinctive behavior (pp. 5-83). New York: International Universities Press.

Wallach, M. and L. Wallach. (1983). Psychology's sanction for selfishness. San Francisco: Freeman.

Wilson, E. (1984). Biophilia, Cambridge: Harvard University Press. 